\title{
Design and Implementation of Financial Accounting System for Small Business Company
}

\author{
Fuping Zhou \\ Guangzhou College Of Technology and Business, Department of Accounting, Guangzhou huadu 510850
}

Keywords: Information, Financial Systems, Small Businesses

\begin{abstract}
Informatization has become the main theme of the 21 st century, the global informatization wave caused by modern information technology impacts on the traditional social life in every corner. The global economy informatization has a tremendous impact on the traditional business management and the accounting system, urges the financial calculation system to transform rapidly. Analysis shows you how to make financial and information technology integration, how to financial information as the management of information resources, comprehensive use of computers, networks and communications information technology and security, to the acquisition, processing, transmission, storage, applications, and other processing.
\end{abstract}

\section{Introduction}

Existing financial systems software system in the specific use of each unit, you need to enter a lot of initialization data, the larger the process workload[1]. Despite the huge volume and the system, but most popular type of module is designed in accordance with the general rules, and each unit has its own independent features many users want to increase according to their specific circumstances some of the features they need, but it is difficult. Financial systems software development[2], computer programmers tend to rely mainly on the main developers conducted their program design, computer programming languages, databases, and other professional knowledge is quite rich, and the operation of financial processes, financial, accounting, auditing and management little is known about other aspects of knowledge, and thus the formation of such a situation: although computer, network technology and constantly upgrade the financial function and efficiency is almost stagnant[3]. Although some units in computer science Personnel and accounting staff combined to develop system software, but it will drag on longer development cycle, involving a wide range of people, it will affect their daily work, measured from the economic point of view, less efficient, so fewer such cases, you cannot meet the actual needs.

\section{The Main Form and the Associated Structure of the Database}

It involves a database table includes : Ledger with the basic accounting data, records, accounts and other accounts associated parameters: As subjects Coding, such as personal accounts and secondary accounts; Associated with the accounting documents : comprehensive information and documents as proof of entry information ; And calculation of secondary data, records, accounts, account balances, loan amount, balance, and other associated intermediate data : In the event of the amount of balance, a secondary account balances, balances of accounts, account balances, personal loans, and so on ; System database table system and its relationship with the accounting business process, as shown in figure 1 : 


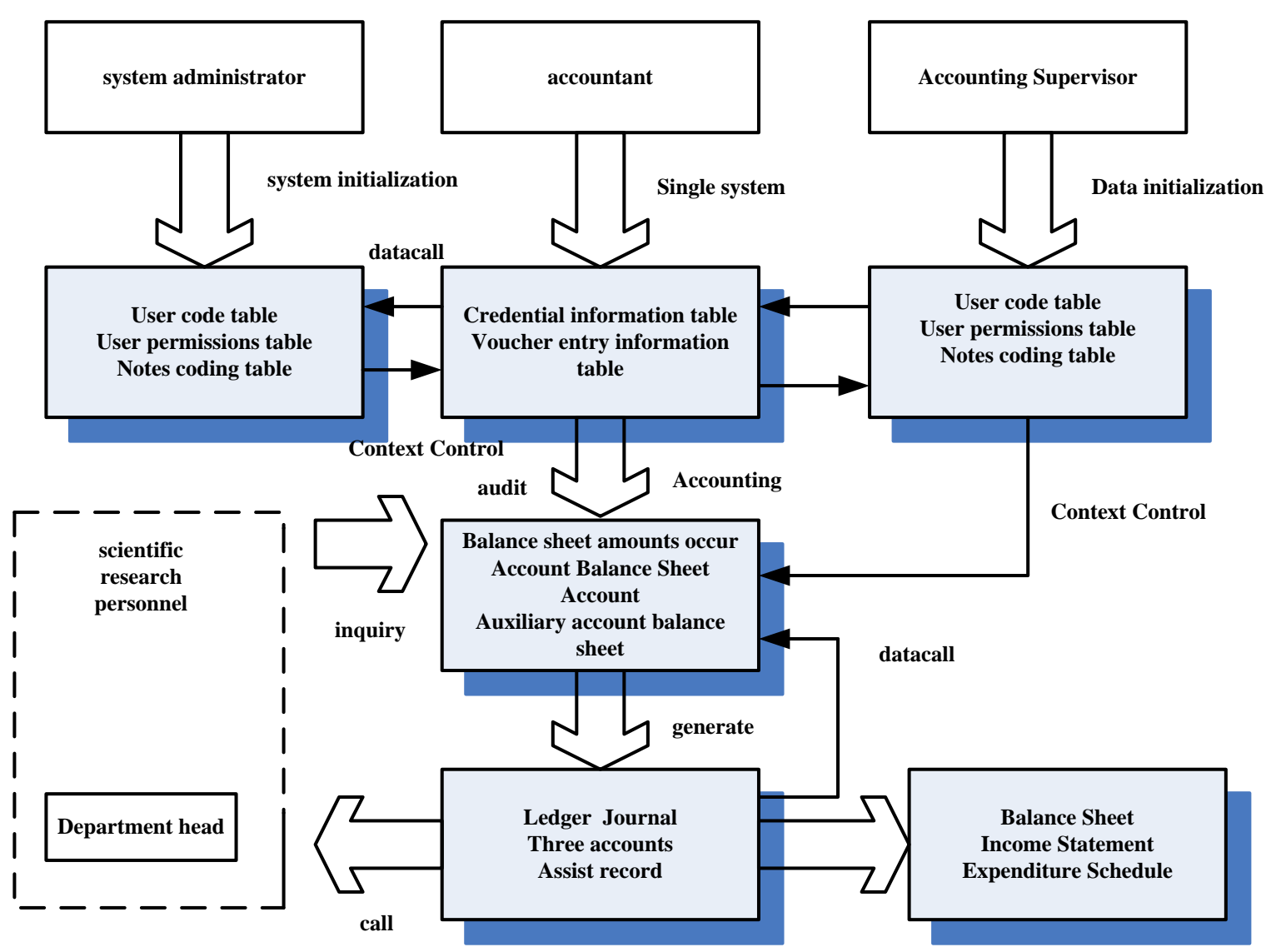

Fig. 1 Small Business Financial Management System Computer System and Database Tables and Accounting Business Process Diagram

\section{Description of the credential information table}

In the system "voucher comprehensive information sheet" Records, mainly credentials primary information, including: such as the date of the voucher number and single and major accounting information. A record of the database will correspond to a piece of accounting documents and the accounting business.

Design of field with the number, the date ( month and day ), Category, status, and so on, in spite of the numerous, but one of the indispensable is the " voucher number ", this will be the primary key, as the basis of the index in the future, their data types are automatically numbered, which identifies each record.

Text field "status", you can use 1, 2, 3, 44 different values, respectively, said: "Is not sent to the voucher ", " have been sent to the voucher", " approved credentials ", " account credentials ", the four different states. The value of a field represents an accounting record processing time progress and identify effective nature of the accounting data.

Provision for payment of payroll module to individual workers wages based on the raw data, calculate wages, payroll processing. Generally include basic setup, the wage structure, wage change management, payroll data processing, payroll report management functions.

\section{Reunification and design techniques and their implementation}

Provision for depreciation of fixed assets is the period of time to compensate for the loss of fixed assets depreciation of fixed assets in accordance with the provisions of the extraction rate of depreciation of fixed assets, or the provisions of national accounts unified virtual computing depreciation rate depreciation of fixed assets. The method has an average life method, method, double declining balance method and the sum method.

General ledger (accounting treatment) module mainly accounting documents to the original data, 
according to accounts, the economic system of statistical indicators contained in the content vouchers, recording, classification, calculation, processing, aggregation, output General Ledger, details ledgers, journals and other auxiliary books, documents and reports. It is the core of financial accounting information systems, sales accounting, material accounting, fixed asset accounting, payroll accounting, cost accounting, general ledger and other modules are centered in the transmission of information to each other.

Internet subsystem the transaction request is sent to the bank server - side front - end computer security, net safe client receive transaction request ( HTTP), after encryption ( https mode ) transfer to the bank - side encryption server, bank - end servers after the decryption process and returns the results to the server in the Background group, so that the web of financial accounting system in colleges and universities and the banks have been established between a virtual HTTP link. In figure 2 indicate the system is running.

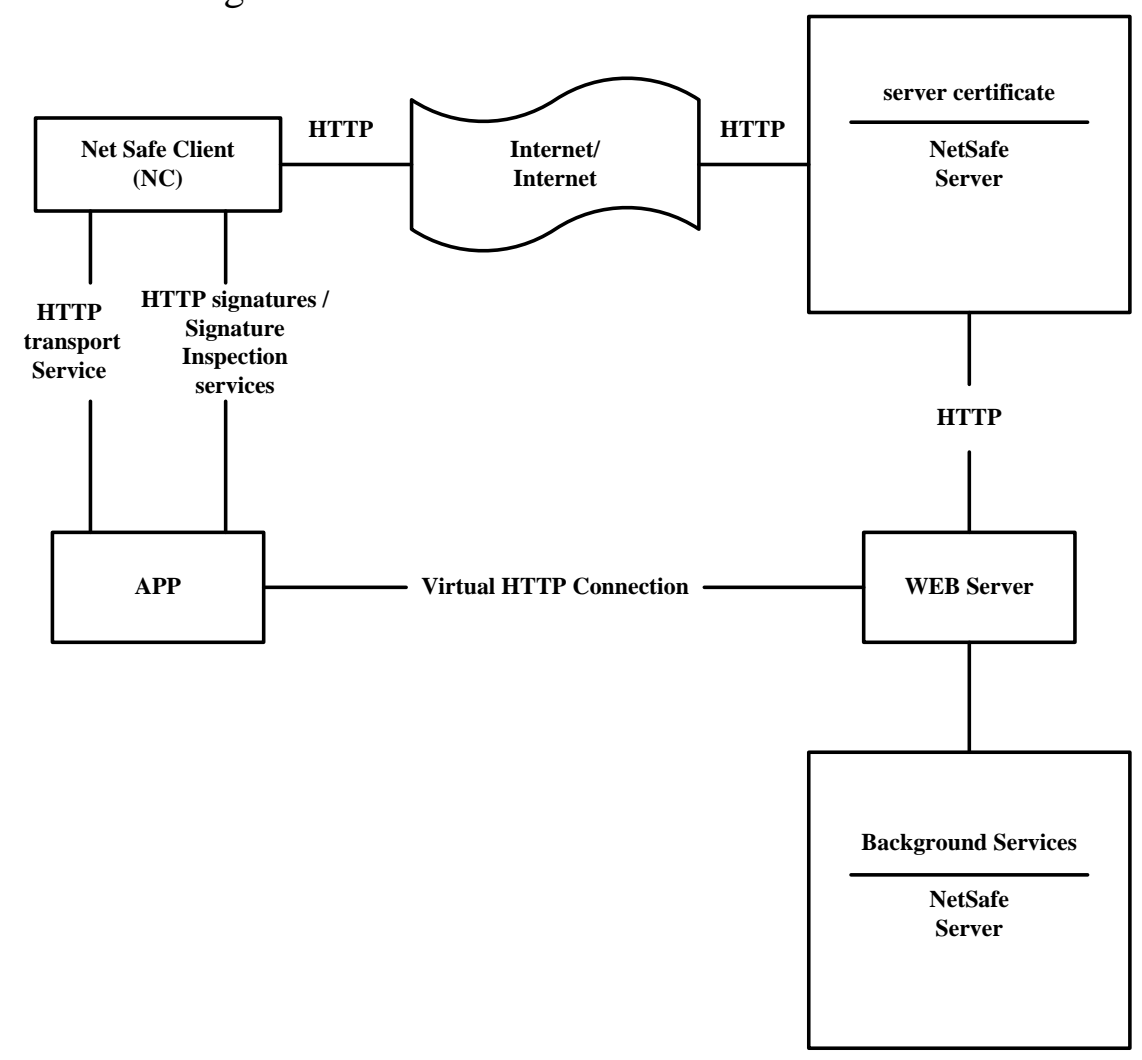

Figure 2 "Silver School Internet" subsystem running process schematic

Small Business Server is called net safe client. It has two can configure the ports used for encryption and signing / verification check services, as shown in figure 3 ( assuming port L for encrypted Port, Port 2 for the signature / Sign Inspection Ports ). When the specific use, "Silver School Internet" sub-transaction requests submitted to the bank, can follow the http protocol port to Net Safe Client 1 sends the request. After receiving the request, Net Safe Client license to use the school http request packet will be converted into https request packet sent to the bank client server. If you need to sign some data, then interconnected system needs to send the signed data to port 2, and then accept the results of the signature port 2, then transaction data to port 1 that contains the signature information and complete the transaction request. 


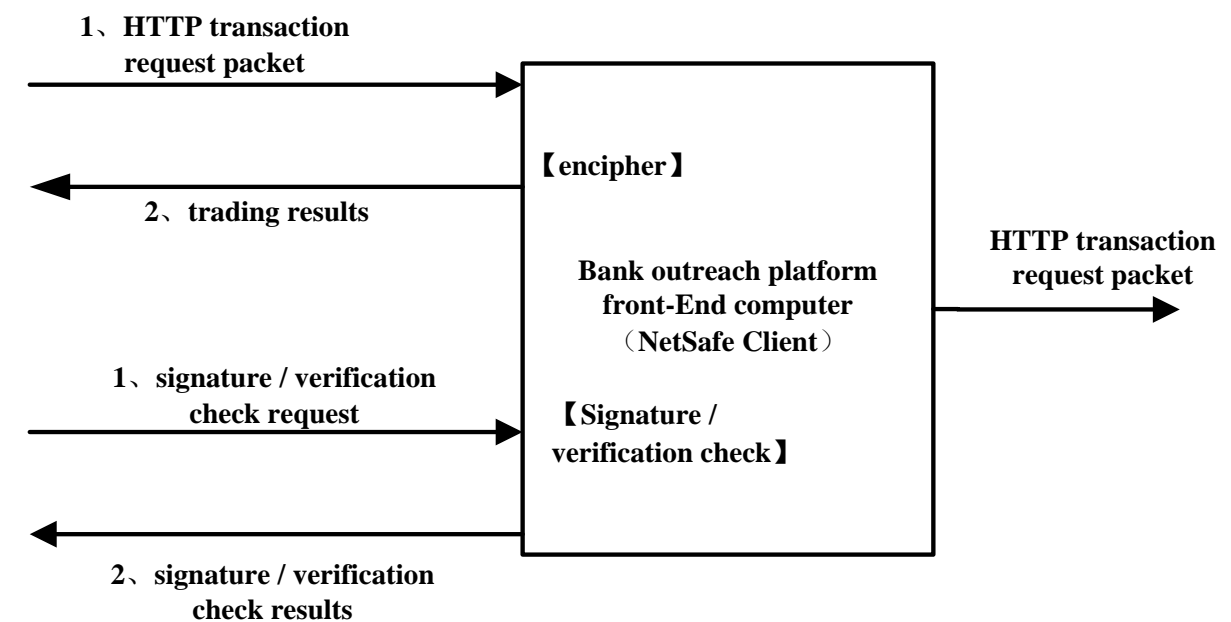

Fig.3 Small Business - side security server running diagram

For convenience, two of the net safe client service ports can be logically called the two servers netsafeclient Encryption and Signature server. "Silver School Association" supports a number of banks online banking platform applications, due to differences in the banking system, the subsystem application of a variety of communication techniques for docking, including win socket communications, http(s) communications and harmonic means of communication functions.

\section{Summary}

"Small Business financial management of computer systems" following the Treasury's latest estimate the direction of reform and the latest financial and accounting system at the same time, give full play to the processing power of a computer system, reduce the intensity of financial management, the financial sector and the budgets of other departments full communication of information to ensure that small businesses to scientific and rational use of funds. I believe that with the improvement of information technology and financial management, accounting software will become an important tool for financial accounting and management. Best financial software can significantly improve the financial level and efficiency of work, management of personnel resources to achieve the standard, scientific management.

\section{Acknowledgements}

Guangdong Provincial Education Department: application oriented laboratory training room (2015WQNCX158) project support.

\section{References}

[1] F. Chen: Current Problems and Suggestions of financial software (Ms. D., Finance and Accounting in Fujian Institute of Research on Accounting, China 2009), p.142.

[2] J.L. Gao: network database technology (Publishing House of Electronics Industry, China 2009).

[3] K.Y. Zhang, C.F. Wu: Network Security Technologies and Applications, Vol. 9 (2011), p.46. 